\title{
Integrating AHP and GIS techniques for rural landscape and agricultural activities planning
}

\author{
Rovai, Massimo \& Andreoli, Maria \\ Dept. of Agricultural, Food and agro-Environmental sciences (DAFE), University of Pisa, \\ Italy
}

\begin{abstract}
This chapter aims at providing some insights on the usefulness of the analytic hierarchy process (AHP) in the context of geographic multi-criteria analysis applied to GIS techniques for empirical applications. The increasing complexity in planning and programming applied to rural landscape and territories asks for multidisciplinary and transdisciplinary approaches based on a holistic knowledge system. The AHP allows organizing in a hierarchic way both quantitative and qualitative information related to different disciplines, usually expressed in incommensurable measure units. Participatory approaches can be included either through information based on the perception of the value of indicators (criteria) or by providing weights on the relative importance of the elements included in each hierarchical level. When applied to GIS techniques, the AHP allows taking into account both spatial distribution of elements/information and their physical relations, which are paramount for the analysis of interventions about landscape, biodiversity, etc. This chapter illustrates four case studies from Tuscany Region (Italy) where this approach has been applied. Results highlight the flexibility of this approach in planning, programming and designing specific interventions where several biophysical characteristics of a territory or landscape have to be integrated with socioeconomic information both at territorial and farm levels. Results show that it is possible to increase the effectiveness and efficiency of tools for the territorial governance by applying a scientifically sound approach that does not ask for complex mathematical models and provides a methodology and results that can be understood also by "non-experts", improving participation processes.
\end{abstract}

\section{Introduction}

The case studies presented in this chapter have been developed through a 10year time span and have as a common denominator the use of the Analytic Hierarchy Process (Saaty 1980, 2004, 2008) as a decision support tool. 
Many policy instruments and specific interventions are based on concepts such as the ones of sustainability (see, e.g. Graymore et al. 2009; Gomez Limon and Riesgo 2009; Sands and Podmore 2000), landscape quality (see, e.g. Daniel and Vining 1983; Fry et al. 2009); vulnerability (see, e.g. Villa and McLeod 2002; Barnett et al. 2008), risk of negative effects, e.g. due to forest fires (see, e.g. Van Wagner and Forest 1987; Chuvieco et al. 2010), level of disadvantage based on natural constraints (see, e.g. Eliasson et al. 2010), which can be associated to composite indexes (OECD 2008) or criteria depending on several elementary indicators, usually organized hierarchically. These phenomena can be studied by analyzing; 1) current situation, 2) past trends, 3) drivers of change, 4) most likely future evolutions and 5) policy responses in the case that either the current situation or the expected trends ask for them. AHP can help to manage data and to organize them in several information layers which can be related to each other. As regards rural areas, in order to design proper interventions, it is important that analyses take into account not only biophysical characteristics of a territory (related to land suitability to agricultural uses) and land cover or land use, but also the role of farmers' decisions in determining a bundle of potential effects (e.g. in term of Ecosystem Services provision) in specific locations, since farmers' strategies are the main drivers of agricultural and rural landscape changes (Primdahl and Kristensen 2011; Van Zanten et al. 2013). In their turn, farmers' decisions are influenced by market trends and policy tools, but depend also on farm structure and bio-physical features of the land farmers manage (see, e.g. Fastelli et al. 2017).

Higher profits deriving from land development compared with the income from cultivation has brought about inefficient and persistent soil consumption (ISPRA 2017) and the creation of relics of farmland enclosed by built-up areas. This approach driven by economic interests has determined an underestimation of the importance of open spaces especially in areas of urban-rural fringe that have not been properly managed, and consequently it should be abandoned. In this case it is important to have a clear vision not only of the productive function of open spaces, but of the whole bundle of Ecosystem Services (ESs) they are able to provide. On the other hand, as stated by Cooper et al. (2006) and Pelorosso et al. (2011), the abandonment of agricultural activities may result both in a loss of ESs provision, such as hydrologic regulation, and of landscape value, especially in the case of cultural landscapes. Indeed, woodland abandonment can bring about several problems related to: a) landslides, due to the excessive weight of trees that are no longer cut; b) the development of vegetation more suitable to ignition; $c$ ) the abandonment of the minor road systems, causing problems of accessibility; and, d) the lack of custodianship and maintenance of the ancient hydraulic works protecting from floods. Thus policy tools influencing agricultural activities should take into account the whole spectrum of ESs that these activities can provide. Due to the negative effects of abandonment, in some of the case studies presented, the economic aspects have been considered as prerequisites for the permanence of agricultural activities in a territory, rather than as ESs belonging to the productive function. 
Where the spatial distribution is relevant, it is possible to integrate AHP with a GIS approach (see, e.g., Malczewski 1999, 2006a; Greene et al 2011). In this case, the analysis often aims at individuating spatial ambits that are homogeneous as regards relevant criteria. Indeed, ex post analysis of the effects of policies impacting on agriculture and environment have highlighted that spatial models are more suitable to achieve an effective policy, if compared to non-spatial regression models (Yang et al. 2014). After the adoption of the European Landscape Convention (Council of Europe 2000) innovative policy directions focusing on designing measures appropriate for different contexts and scales have increased (Conrad et al. 2011).

According to Magnaghi (2005) a territorial project should be considered as the reference scenario that should guide both specific actions and projects, and the strategic assessment of operational projects and policies, by referring to evaluation parameters which can be continuously reformulated in relation to the information acquired in the process. The need of information at local/detailed level and of updating them frequently makes it difficult to base policy decisions on information that are exclusively depending on external sources and that often are also quite difficult to be interpreted, as in the case of complex mathematical models. The lack of awareness about the impact of policies can encourage decision-makers to take decisions on the basis of lobbying or economic pressures, rather than of objective analyses (Marson 2010).

Recently, there has been a growing diffusion of web-GIS tools based on Multicriteria Analyses (Labiosa et al. 2010, 2013; Jackson et al. 2013; Tallis et al. 2011) allowing to integrate a great amount of information and models typical to different disciplines by homogenizing the information. They provide a useful decision support system to problems that are not completely structured and aim to determine a final score (a-dimensional and expressed in relative terms) allowing to individuate a hierarchical order of the alternatives, e.g. from the best to the worst one. These tools can be useful especially when analyses and policies are related to regional/local ambits and to operational tools.

In this framework, after describing the main features of the methodological approach integrating AHP and GIS, this chapter presents some empirical studies at increasing level of complexity, in which at least one of the Authors has been directly involved, in order to highlight how the general methodology has been adapted to each specific problem and the results obtained.

The chapter is organized as follows. After this introduction (1), a paragraph on the methodology (2) is given, distinguishing the general aspects by the specific ones which are characterizing the four case studies presented. In this paragraph also a short description of Tuscany, the Italian Region where case studies are located, is given. Paragraph 3 presents the results of the case studies, while paragraph 4 provides a general analysis of strengths and critical points of the proposed approach. 


\section{Methodology}

All the case studies presented in this contribution have employed Geographic Multicriteria Aiding Techniques able to rank the spatial alternatives under study according to their specific and often conflicting evaluation criteria, which are represented through standardized map layers (Malczewski 1999, 2006a, 2006b). Among the several multicriteria analysis techniques described in literature (Beinat and Nijkamp 1998; Mendoza and Martins 2006), the multiattribute Saaty's Analytic Hierarchy Process (AHP) has been chosen. AHP constructs the evaluation process through distinct phases assuming as a principle the possibility to segment a complex decision-making problem into smaller and simpler sub-problems composing a hierarchical structure, within which it is always possible to measure the influence each part has on the whole system. The hierarchical structure is organized in three levels: goals, criteria, and alternatives, where criteria can be detailed in attributes and sub-attributes, in order to reach elementary indices, represented by cardinal or ordinal values that can be reliably measured or assessed. In the case of AHP integrated with GIS, alternatives are spatial and they can be represented by points, lines, polygons or pixels that contain the attribute values. The presented case studies deal with situations where the relevant spatial unit varies from polygons referring to a regular grid in which the territory has been subdivided, to plots of land with homogeneous characteristics, up to the land managed ${ }^{1}$ by an agricultural enterprise, considered as a single decisional business unit.

The advantages of AHP are related to the following features:

- It is possible to use not only quantitative but also qualitative information, provided that they can be ordered. The transformation of information in Saaty's semantic scale allows comparing attributes expressed in different measure units.

- The AHP hierarchic structure allows analyzing phenomena described by criteria that in their turn are related to attributes and sub-attributes, thus allowing the representation of complex problems, as the ones that have to be faced in dealing with sustainability or integrate territorial planning.

- AHP allows confronting the performances of alternatives, represented by decisions, e.g. in terms of alternative policy designs, or by territorial units. In the case of integration of AHP with GIS techniques the result of the analysis is usually a characterization of the space through its subdivision in ambits which are homogeneous as regards the goals/criteria included in the analysis.

\footnotetext{
${ }^{1}$ Through databases related to Common Agricultural Policy aid it is possible to individuate the cadastral parcels that are managed by each farm. Cadastral data refers to the Italian inventory of agricultural land (Catasto Terreni), where the elementary unit is a parcel of land belonging to the same Municipality, holder, category of agricultural utilization and class of productivity that is not divided by roads, rivers, railways, etc.
} 
All the case studies presented are located in Tuscany, an administrative Region in the Central-Western part of Italy. Tuscany has a territory of about $23,000 \mathrm{~km}^{2}$, which is mainly hilly $(66.5 \%)$ and mountainous, while plains account only for $8.4 \%$ of the whole territory, and it has a population of ca. 3.7 million inhabitants. Tuscany is famous worldwide, due to the beauty of its rural landscape, often characterized by the presence of urban structures dating back to the medieval and Renaissance age, together with fortified villages, scattered rural and religious buildings, and to its cities of art (Rovai et al. 2016). According to Ciampi et al. (2015) in Tuscany on average in 2013 artificial areas accounted for about $8.6 \%$, agricultural areas for $38.1 \%$, natural and semi natural areas for $52.3 \%$, and water bodies and wetlands for $0.9 \%$; these average figures hide a high variability among areas; artificial areas, e.g., account only for $5.3 \%$ in the mountains and for $7.5 \%$ in hilly areas, but raise up to $33.9 \%$ in the lowlands. Agricultural land use is the most important one in hills and lowlands, where it accounts for $68.0 \%$ and $57.4 \%$, respectively, while natural and semi natural areas are prevalent in the mountains where they account for $75.3 \%$. In the period 2007-2013 agricultural areas decreased by 5,800 hectares, mainly due to artificialization processes and, in some areas, due to an increase of woodlands (Ciampi et al. 2015). Furthermore, the urbanization model is very often characterized by low density, with a high consumption of soil for each inhabitant.

The case studies are presented in order of increasing complexity. The first one deals with a specific and technical problem, i.e. the spatial analysis of the level of risk of forest fires, in order to plan the best ways to prevent and face them. The second one deals with the problem of land abandonment in a rural area and the individuation of policy instruments that could lead either to a recover in terms of productive use or, when this is not economically sustainable, to reduce the risks coming from a "sudden" renaturalization after a long period of anthropic pressure. The third one deals with problems of open spaces in areas of urban sprawls and in the characterization of the main ESs provided by different portions of a territory. The last one proposes a model for the sustainable governance of the rural cultural landscape of Val d'Orcia, which is one of the UNESCO heritage sites.

\subsection{Territorial assessment of the risk of forest fires in Livorno (Leghorn) province}

This first case study ${ }^{2}$ concerns the design of a plan for forest fires in Livorno province (Italy). Italy, especially in its central and southern areas, is very prone to forest fires due to its bio-physical characteristics and hazards of anthropogenic causes, often related to arson with the aim of allowing the development of burnt

\footnotetext{
${ }^{2}$ The methodology applied for this case study is described in details in Candura (2005), although some improvements to the initial methodology have been introduced.
} 
land. Italian legislation requires that every Region adopts a Plan for forecasting, preventing and actively counteracting forest fires. In this application the goal of the GIS-AHP analysis was to assess and map the risk of forest fires in order to provide a scientifically sound basis for actions aiming to reduce and mitigate this risk. The methods that are more frequently employed for simulating the frequency or the probability of fire events use GIS-based MCA tools to produce risk maps. In other cases, it is proposed to employ geoprocessing routines based on algorithms able to interpret input maps (Gai et al. 2011). While many studies regarding forest fire risk (Arpaci 2014; You 2017) deal with factors affecting the probability of fire, in our model, as in Hardy (2005) the entity of risk, for each area, has been assumed to depend on:

- The probability $(P)$ to have a forest fire in a predefined time period,

- The entity of consequences of forest fires, i.e. damage $(D)$ that they will cause in terms both of economic losses of productive activities and of environmental negative effects.

In our model the Risk $(R)$, in analogy to the definition of risk in the case of safety problems, is given by the product of the probability of an event $(P)$ and the damage $(D)$ it would cause, i.e.

$R=P \times D$

Thus, while Probability measures the chance of a forest fire in each area in a predefined time period, Damage estimates the consequences in terms of loss of economic and environmental values in case of forest fire.

The provincial territory of Livorno has been subdivided in 119.922 units by a grid of 100x100 m and each elementary unit has been described by means of the data of the Regional GIS through criteria and attributes related to fire-related risks. Probability and Damage criteria have been described by separate hierarchical trees, by considering the attributes derived from literature and by interviews to key informants, and initially mapped as separated criteria. Then a composite index of forest fires risk has been computed, under different scenarios as regards the weights to be assigned to each attribute.

In accordance with other contributions (Jaiswal et al. 2002; Arpaci et al. 2014; You 2017) the criterion assessing the probability of forest fires has been related to the following attributes:

1. Topographical factors, described by: Altitude, Slope and Orientation (subattributes)

2. Climate factors, described by: Temperature, Precipitation, Wind (subattributes)

3. Land cover factors, described by Land cover ignitability (sub-attribute)

4. Human activity factors, described by: Proximity to roads and Number of tourists (sub-attributes) 
The criterion assessing the entity of damage has been related to the following attributes:

5. Economic Value, described by: Average value of agricultural land (VAM) (Ciancio et al. 2007; Blahut et al. 2014); and Presence of infrastructures, such as power lines and methane pipelines (sub-attributes);

6. Environmental Value, described by: Presence of areas with Environmental constraints; Presence of Areas with Archaeological constraints, Presence of areas with Hydrological constraints; Presence of Protected areas (e.g. Natura 2000 areas).

For more details on data sources and how sub-attributes have been calculated, see Candura (2005).

In order to compare attributes expressed in different measure units, they have been normalized to a $0-1$ range. According to the type of attribute, the following three normalization methods have been used:

1. Linear scale transformation, using a direct or indirect relation between raw data and normalized ones depending from the fact that a high value of the raw datum was increasing or decreasing the probability or the damage entity of forest fires;

2. Expert evaluations, when functions relating raw data and probability or damage entity of forest fires were not available;

3. Probability method, when the relation has been estimated on the base of a statistical analysis relating forest fires and the features of the areas where they have developed. This analysis was performed on a random sample of $50 \%$ of the elementary units.

After normalization, the computation of criteria has been performed under the hypothesis that all sub-attributes and attributes had the same weight, thus obtaining two separate maps: the first one measuring the probability of forest fires and the second one measuring the entity of economic and environmental damages in case of forest fires.

Lastly, in order to assess the risk in its components of probability and damage entity, four different scenarios were built under the following hypotheses about weights:

- Scenario 1: all criteria and attributes have the same weights

- Scenario 2: human activity and land cover factors have a higher importance than topographical and climate factors in influencing forest fire probability and environmental values are more important than economic values when assessing the entity of damages;

\footnotetext{
${ }^{3}$ VAM (Valori Agricoli Medi) are the average real estate prices for land with agricultural destination and have been mostly used in case of compulsory purchase, i.e. when a state or a national government takes private property for public use. They are individuated at provincial level.
} 
- Scenario 3: human activity and land cover factors have a higher importance than topographical and climate factors in influencing forest fire probability and economic values are more important than environmental values when assessing the entity of damages;

- Scenario 4: human activity and land cover factors have a much higher importance than topographical and climate factors in influencing forest fire probability and environmental values are slightly more important than economic values when assessing the entity of damages.

The ability of the different scenarios to fit real data (model testing) has been checked by using the sample of $50 \%$ of the elementary units that were not selected for building the model (see normalization phase), thus searching an independent validation of the model.

\subsection{Productive and landscape restoration of a hilly rural area (Pieve di Compito, Lucca)}

The second case study ${ }^{4}$ deals with a territory with strong historical, identity and landscape values, and it is located in a hilly area of Tuscany traditionally characterized by olive groves and currently suffering for severe abandonment problems, partly caused by land fragmentation. Rural areas have not been deemed as very important in the cultural debate on landscape until 2000, when the European Landscape Convention (Council of Europe 2000) caused a new and increasing interest for the maintenance and restoration of rural landscapes. Currently, rural landscapes are not only appreciated for their value from a historic and identity point of view, but also for the economic role they can play for tourism and the high quality produce reputation of an area. The new role of agro-forestry landscapes as a common good to be protected asks for new models aiming to individuate the best intervention strategies for territories characterized by both high landscape value and widespread phenomena of abandonment, and for appropriate governance approaches to implement them. In this case study, AHP has been used to build an "expeditious" model to individuate interventions priority for the productive and landscape restoration of olive groves or, as an alternative, for the transition to woodland, in the framework of the Integrated Territorial Projects (ITPs). ITPs are one of the "collective measures" included in the Rural Development Plan (RDP) 2014-2020 by Tuscany. In this case, as it has been partly done for the analysis of Val d'Orcia landscape described in the last case study, the elementary unit is represented by cadastral parcels. Each elementary unit (i.e. cadastral parcel) has been characterized by means of attributes about the bio-physical features of the plot, the way it is managed by the farmer and its importance in terms of landscape

${ }^{4}$ This case-study has as a main source Bonelli 2017. 
and environmental values. The model has been tested on a small area ( 81 ha ca) in the "Colline Lucchesi" (hills of Lucca province), characterized by small farms where production for self-consumption is prevalent and the main agricultural use is the cultivation of olive trees which, due to an average slope of $45 \%$, are grown on terraces. The model integrates all these aspects with the aim to provide useful information to policy-makers on the specific interventions that would be most favorable for each type of cadastral parcel. The case-study area, as most of the hilly areas in Lucca province with olive groves, has shown increasing phenomena of abandonment since the sixties, due both to fires and to the reduction of the profitability of olive cultivation, together with a cultural change in the local community, where the new generation shows a lower attachment to rural values. A diachronic analysis of the evolution of land use highlights how the area suffered for a noticeable landscape change, due to the abandonment of olive groves, to which renaturalization processes followed (Fig. \#.1).

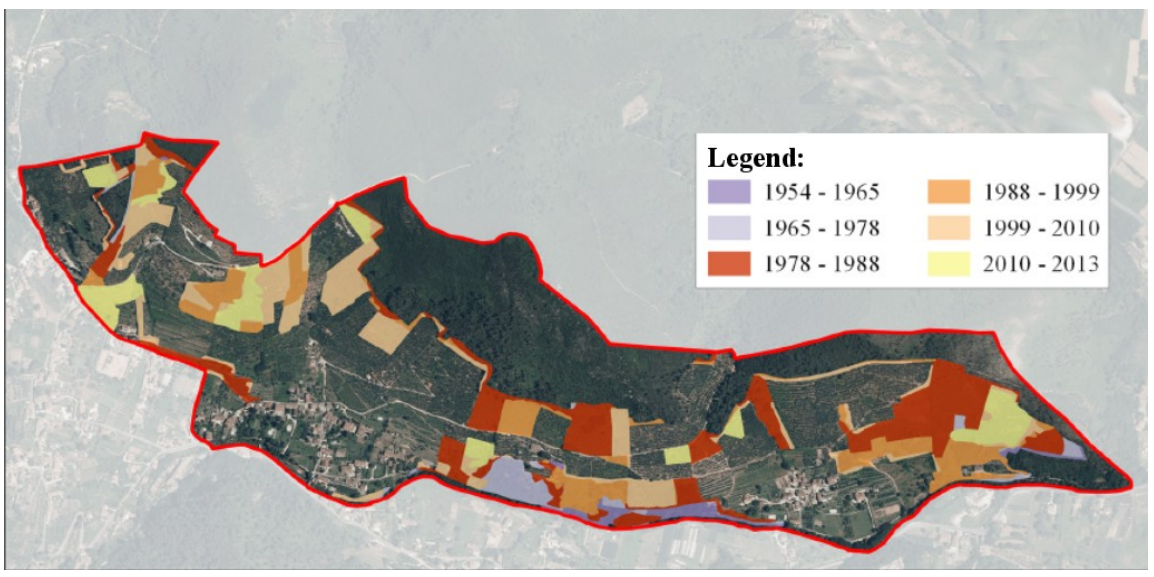

Fig. \#.1. Abandoned agricultural land by period of abandonment - spatial distribution. Source: Bonelli 2017.

The percentage of abandoned agricultural land during each period is described in Table \#.1.

Since the focus of the analysis was on the problem of abandonment, the spatial MCA model has been built:

1. From a spatial point of view, on the layer of cadastral parcels where the agricultural use has been abandoned,

2. Using as a goal the assessment of the possibility of restoration of olive groves and their cultivation,

3. Defining attributes and criteria related to the goal, which could be calculated from available data sources. The creation of the MCA matrix has been done directly in GIS environment in order to use the data collected during the territori- 
al analysis in the more effective way and to profit of the computing power of QGIS software (QGIS Development Team, 2012).

Table \#.1. Abandoned agricultural land by period of abandonment. Source: Bonelli 2017, modified

\begin{tabular}{lcc}
\hline Period & Abandoned agricultural land (ha) & $\begin{array}{l}\text { Abandoned agricultural land on total } \\
\text { agricultural land (\%) }\end{array}$ \\
\hline $1954-1965$ & 0.96 & 1.2 \\
$1965-1978$ & 1.31 & 1.6 \\
$1978-1988$ & 7.32 & 9.0 \\
$1988-1999$ & 4.49 & 5.5 \\
$1999-2010$ & 4.65 & 5.7 \\
$2010-2013$ & 2.99 & 3.7 \\
Total (1954-2013) & 21.72 & 26.8 \\
\hline
\end{tabular}

Table \#.2. describes the 12 criteria considered in the spatial MCA: among them, the first eight have been classified as "Cost criteria" since they deal with the costs for olive groves restoration and management, while the last four criteria have been classified as "Benefit criteria", since they are related to the degree of quality improvement from an environmental and landscape point of view and, consequently, with an increase of community well-being.

Table \#.2. Criteria related to the suitability to productive rehabilitation of abandoned parcels. Source: Bonelli 2017

\begin{tabular}{|c|c|}
\hline Cost Criteria & Benefit Criteria \\
\hline 1. Period of land abandonment & 9. Architectural value of open ditches drainage \\
\hline 2. Size of the abandoned areas & 10. Proximity to cultivated areas \\
\hline 3. Soil average slope & 11. Proximity to inhabited zones \\
\hline 4. Vegetation cover on abandoned land & 12. Aesthetic-perceptive significance \\
\hline \multicolumn{2}{|l|}{ 5. State of maintenance of terraces } \\
\hline \multicolumn{2}{|l|}{ 6. Accessibility (from outside farm) } \\
\hline \multicolumn{2}{|l|}{ 7. Access to farm and forest land (internal) } \\
\hline 8. Management type & \\
\hline
\end{tabular}

A score in the 1-5 range - where the lowest score is related to the lowest criterion value, both for cost and benefit criteria - has been given to attributes belonging to each criterion. Table 3 gives an example of the scores for the attribute "Average slope", whose spatial representation is given in Fig. \#.2. 
Table \#.3 Score attribution to the Criterion "Soil Average Slope". Source: Bonelli 2017.

\begin{tabular}{ll}
\hline Description & Score \\
\hline Soil average slope $</=15 \%$ & 1 \\
Soil average slope $>15 \%$ and $</=30 \%$ & 2 \\
Soil average slope $>30 \%$ and $</=45 \%$ & 3 \\
Soil average slope $>45 \%$ and $</=60 \%$ & 4 \\
Soil average slope $>60 \%$ & 5 \\
\hline
\end{tabular}

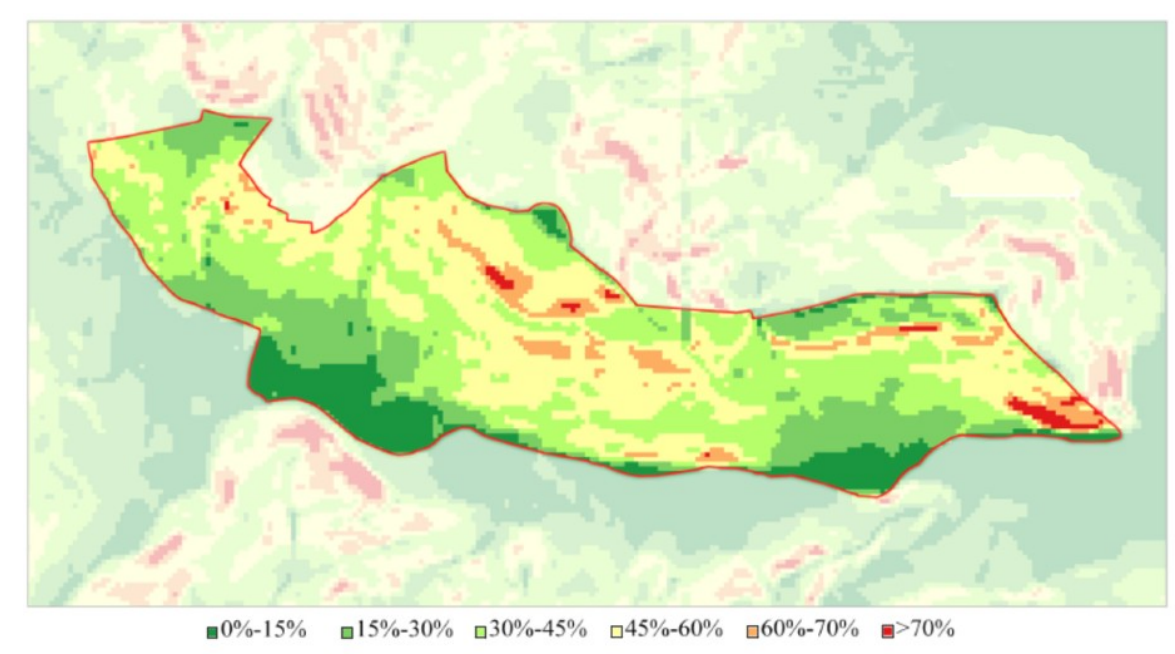

Fig. \#.2. Spatial representation of average slope in the case-study area. Source: Bonelli 2017.

Finally, in order to compute the goal value for each spatial elementary unit, weights were assigned to the 12 criteria. This has been done separately for the two subsets of Cost and Benefit Criteria. The ranking of the alternatives, aiming to assess the degree of parcels suitability to rehabilitation for land cultivation, has been carried out with two methods in order to compare strengths and weaknesses of both of them. The methods were the following:

1. Weighted Sum: for each cadastral parcel the total score has been computed as sum of the weighted values of each criterion. In this case, due to the fact that costs are inversely related with utility, the highest utility level has been assigned to the score 1 of Cost criteria. In this way, all criteria are summarized in a unique cardinal value (goal value), that is available for each spatial alternative (cadastral parcel). While cadastral parcels with a very high value for the Goal show a high suitability to rehabilitation since farm costs are low and community benefits are high, this method has the drawback of not allowing to know if the suitability is mostly due to low costs, high benefits or a combination of good scores for criteria belonging to both classes. 
2. Miles's Value Index: this index has been defined in the framework of the Value Analysis (Miles 1961). When defining the concept of value, Miles introduces a composite index called "Value Index", or $I V$, computed as the ratio between the utility of an entity, i.e. "Worth" or $W$, and its global cost, i.e. "Cost" or $C$.

$I V=W / C$

In this case study, $I V$ has been computed as a ratio between the weighted sums of criteria classified as Benefits and Cost criteria; consequently, the higher is the ratio, the higher is the priority that parcels should have in rehabilitation strategies.

\subsection{Planning in the rural-urban fringe taking into account the multifunctional role of agriculture (Piana di Lucca, Lucca)}

The third case study ${ }^{5}$ deals with a problem of spatial planning in an area (Plain around Lucca) where, due to low density and scattered settlements, there is a strong intertwining between build-up and open agricultural areas. In this case, the AHP-GIS model was used to evaluate the value of the open spaces (i.e. agricultural land) in terms of Ecosystem Services (ESs), in order to give support to policymakers in their planning decisions and to promote strategies aiming to limit soil consumption and abandonment, since both these phenomena have strong effects in terms of ES provision. In past times, due to a gradual loss of importance of the value of agricultural production and a disproportionate ratio between the cultivation income and the construction income, planners have interpreted the open land around urban centers as an unlimited resource for the development of settlements. In recent years, as a result of the growth of a new cultural sensitivity, the use of open spaces, and in particular of agricultural soils, for building purposes is increasingly perceived as a waste, if not an abuse, when not justified by the actual need for improving the quality and welfare of citizens. The strengthening of public awareness about the importance of open and rural land areas to ensure the reproducibility of resources and vital functions, should be a key objective for planning actions for the coming years. This objective should be reflected in the implementation of proper strategies to enhance the value of the open territory, and in particular in the rural areas, as a place of co-production between man and environment where to make the best use of reproductive capabilities of nature (Rovai et al. 2013). In this framework, it is paramount to assess ESs provided by open spaces and the negative impacts on community well-being deriving from the waste of them.

\footnotetext{
${ }^{5}$ This case-study has as a main source Rovai et al. 2013.
} 
The methodology allowed not only mapping the spatial distribution of each specific function, but also finding the relative intensity with which each type of ES or ESs category was provided by an area.

Following the Common International Classification of Ecosystem Services (Haines-Young and Potschin 2013), in this contribution the categories of ESs considered have been reduced by the initial four, i.e. provisioning, regulating, supporting and cultural (Costanza et al. 1997; de Groot et al. 2002; MEA 2005) to only three relating respectively to: productive function, protective function, and recreational and cultural function.

The case-study area is "Piana di Lucca" (lowland around Lucca city), where remains of "Lucca Court", a peculiar rural settlement organization in the open territory that has a great value both from an aesthetic and from a historic and cultural point of view, are still present.

While in the marginal hilly areas vineyards and olive groves have been replaced by natural and semi natural areas, the expansion of lowland settlement typical of urban sprawl is leading to a strong fragmentation of the ecological network and exacerbating hydraulic problems. From 1995 to 2007 the area around Lucca suffered for a gradual decrease of agricultural land, mainly due to the process of urban expansion; this phenomenon caused the loss of 37,000 ha at province level. Besides, agricultural activities suffer for the increased fragmentation of farms in the areas of urban sprawl, which in its turn causes increased costs and organizational problems. For the above reason it was deemed as important to include in local planning an assessment of the values (in broad sense) related to rural areas and to highlight costs and benefits of their conservation.

This case-study area was analyzed trough a GIS-AHP analysis aiming at spatially assessing the three following categories of ESs:

1. Productive services, related to the ability to produce food and agricultural goods and, consequently, economic value;

2. Protective services, related to the ability of open spaces to ensure the preservation and reproduction of natural resources;

3. Cultural and social services, related to the rural environment ability to contribute to the physical and psychological well-being of the community.

Productive services have been estimated through the identification of areas:

1. Which are managed by farmers who have applied for EU contribution, considered as "professional";

2. Where there are Protected Designation of Origin (PDO) products; and

3. By taking into account the degree of estimated profitability of crops.

Protective services have been estimated through the identification of areas:

1. Of ecological connectivity (giving the maximum score to "nodes" and the minimum to "secondary connections");

2. $\mathrm{CO}_{2}$ sequestration capacity, and; 
3. Ability to recharge the aquifers.

Cultural Services have been estimated through:

1. The persistence of the historical settlement system;

2. The topological relationship to the settlement system, i.e. the Intervisibility between settlements and agricultural land portions, and;

3. The proximity to high population areas, considered as a proxy of the number of people who can benefit from these services.

The elementary spatial unit was a hexagonal grid having a size of about 1,000 square meters.

While it would have been possible, through AMC, to summarize the total importance in terms of provision of ESs belonging to all the three categories described above, the Authors deemed more important and useful, as a cognitive framework for planning, to individuate the vocational destination in terms of ESs provision of each homogeneous ambit of the territory. This result was technically obtained by using a three-dimensional color gradient built through the integration of the three RGB channels of a 24-bit image, where red was related to Cultural services, green to Protective Services and blue to Productive Services.

\subsection{Sustainable governance of a cultural-historic landscape (Val d'Orcia, Siena)}

The fourth and last case-study ${ }^{6}$ deals with the demand for new landscape planning tools deriving from the adoption of the European Landscape Convention in 2000 (Council of Europe 2000). This case-study analyses the situation of Val d'Orcia, one of the Italian UNESCO heritage sites, and it identifies future landscape scenarios by integrating past evolution (historical analysis), landscape sensitivity (territorial analysis) and farmers' adaptation to market and policy changes (farm analysis). In this framework, policies are considered both as drivers, since Common Agricultural Policy (CAP) has often had a negative influence on landscape, and as responses to landscape change. This case-study presents a model for the governance of rural landscapes (Fig. \#.3.) that is based on the integration of a geographical multi-criteria analysis and advanced GIS-based geo-processing tools (Rovai et al. 2016). The spatial elementary unit considered varies depending on the features that are analyzed; thus, there are attributes described on the base of a regular grid; attributes related to plots as an elementary unit with homogeneous agricultural destination, and attributes related to the farm as an economic unit.

\footnotetext{
${ }^{6}$ This case-study has as a main source Rovai et al. 2016.
} 


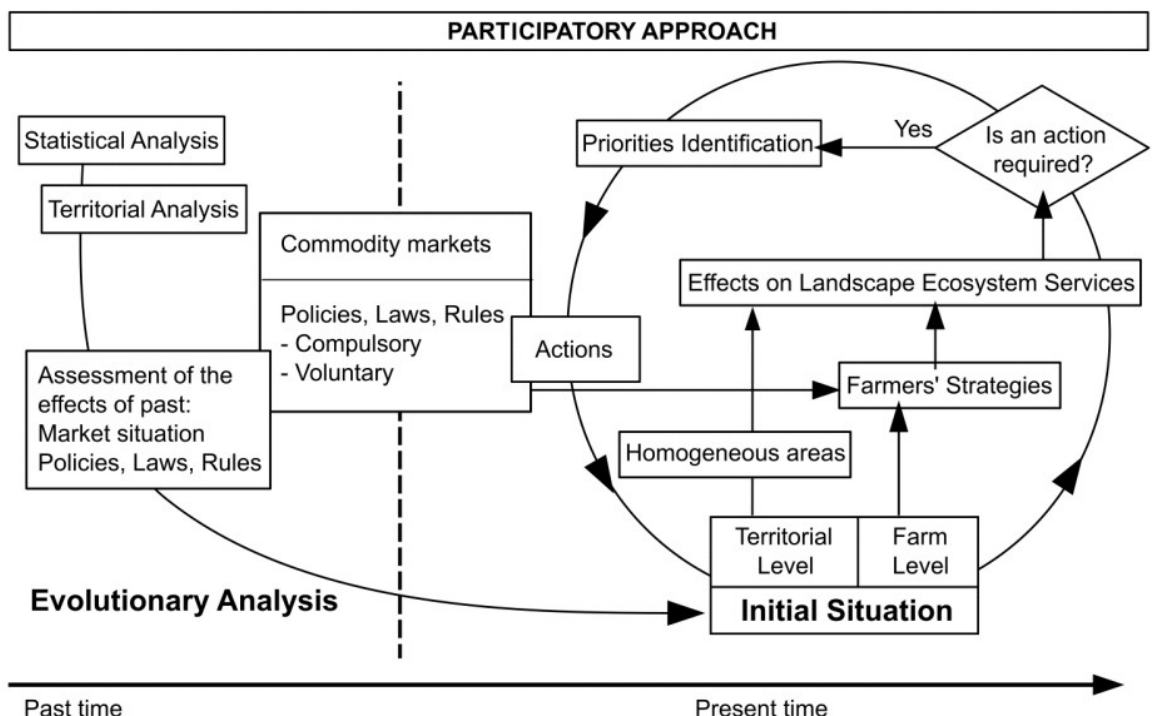

Fig. \#.3.. Flow chart of the model for the governance of sustainable rural landscape. Source: Rovai et al. 2016.

AHP integrated with GIS techniques has been used in the analyses at territorial and farm level. The territorial analysis is necessary to classify a territory into homogeneous ambits as regards the level of ecosystem services that they are able to provide and the risk that anthropic activities might negatively impact on them. As in many other studies concerning the risk of loss of ecologic, environmental or cultural values, the problem was faced with a twofold approach. First of all, the areas characterized by higher values were identified, in order to be able to rank territorial units from the ones most deserving interventions to the ones whose value was deemed as negligible; in this case the aim was to classify areas in homogeneous ambit in terms of "Intrinsic Value" and the spatial elementary unit was a regular square grid. Then, the same areas were classified in order to assess their level of "Vulnerability". Crossing the two above classifications it is possible to obtain a matrix giving priorities for the interventions: the highest priority relates to territories with high value and high vulnerability, while at the opposite end of the hierarchy there are territories with negligible value and low vulnerability.

In both cases, criteria were organized in attributes and sub-attributes chosen among those commonly used in landscape ecology approaches (Farina 2006). The criterion "Intrinsic Value" was depending on two attributes, i.e. "Historical and Environmental Value" and "Frequentation"; this latter was introduced under the hypothesis that Historical and Environmental values were not only important for themselves but also insofar as they could be enjoyed by somebody. In its turn, the "Historical and Environmental value" of each ambit was depending on the values 
of several sub-attributes, i.e. Fragmentation, Persistence, Uniqueness, Integrity and Visibility, for which rules for attributing a score were given, based on literature and participatory approach. Vice versa, in the case of "Frequentation" it was possible to directly attribute a score. For a detailed description of criteria and attributes used in the analysis, see Rovai et al. (2016). The territorial analysis allowed individuating and locating zones with similar level of importance for community wellbeing and vulnerability to the modifications induced by anthropic activities.

While the territorial analysis aims to classify a territory in homogeneous ambits, farm analysis aims to highlight the most likely effects of farmers' strategies, seen as the main drivers of change in agricultural landscape. Intensification (Stoate et al. 2001) and abandonment (Cooper et al. 2006; Pelorosso et al. 2011) of agricultural activities may result in a loss of ESs provision and of landscape value, but in this case - due to the specific bio-physical characteristics of the area - we deemed abandonment to be more likely and more dangerous than intensification. Farmers' strategies are heavily depending on farm structural, socio-economic and management characteristics but also on the quality level of available resources in terms of land suitability to cultivation. While the first characteristics have to be analyzed at farm level, intended as the business unit were decisions are taken, the second characteristics mainly depend on bio-physical features and consequently had to be analyzed at plot level. Plot and farm levels were related by attributing to each farm the plots it was managing. The analysis at farm level had the aim to understand the degree of resilience of business units in relation to policy and adverse market trends, due to its structural and organizational features, while the analysis at plot level had the aim to investigate their suitability to cultivation. This latter differs from the commonly used concept of land capability insofar as it depends from characteristics, such as scale/morphology, that are more influencing farm organization and costs than land productivity, while variables like climate, that was considered to be quite homogeneous due to the small scale of the case-study area, were not taken into account. By combining the analyses at farm and plot levels it was possible to forecast the level of adaptation and capacity to survive either as business unit or productive resource of local agriculture when confronted with external negative impacts; indeed at territorial and landscape levels the exit of a business unit from the market has a different impact from the abandonment of land as a productive resource. Thus a decrease in farmland could have a very different and worse impact than a decrease in the number of farms.

The analysis at farm level aims to provide information on the areas that are at risk of abandonment or strong extensification, with negative impacts due to the abandonment of the agricultural activity and its custodianship role. Moreover, farms with different resilience to adverse trends react in a different way to the possible policy tools that could be implemented in order to promote landscape sustainability; consequently a good knowledge of their features and how these could affect farm's strategies is very important when designing policy tools. 
The final values of plots' suitability to cultivation and farms' adaptation capacity to negative impacts have been parted into three classes (low, medium, high) with the aim to compute, in accordance with fuzzy logic (Boroushaki and Malczewski 2010; Karsak 2004) the probability of each alternative to belong to each class (see Rovai et al. 2016). Then, a cross-reading phase has been carried out via a fuzzy logic in order to compare and integrate the two composite indices and identify a set of farm evolutionary paths/strategies deriving from crossing the classes (L, M, and $\mathrm{H}$ ) of plots and farms. These strategies are described and discussed in the paragraph of results.

It is important to stress that the setup of the model and the validation of intermediate results have been carried out with the involvement of local stakeholders through individual interviews to key informants and focus groups. Interviews have been based on open-answer questionnaires and mainly used to gather information for the analyses, such as attribute and sub-attribute to be considered and their scores. Focus groups, which have involved representatives of associations of the territory and farmers, have been mainly used for checking the results of the analyses and for discussing actions to be taken. In particular, focus groups have explored the willingness/motivation to develop actions/products within a participative approach with the aim to promote an "environmental requalification" of Orcia Valley landscape; this with the aim to promote a participatory and transdisciplinary approach.

\section{Results}

\subsection{Territorial assessment of the risk of forest fires in Livorno (Leghorn) province}

The analysis of forest fires in Livorno province allowed to produce a series of thematic maps for sub-attributes, attributes and criteria, as the one reported in Fig. \#.4, which represent the maps of the four attributes describing the criterion "Environmental value".

The methodology allowed producing also the mapping of the composite index estimating the risk of forest fires, according to the four different scenarios described in the methodology. These were tested by using the random sample of $50 \%$ of elementary cells that had not been used in the normalization process. The scenario which best fitted statistical data, i.e. with the highest number of coincidences between the model and the effective situation, was Scenario 4 . 


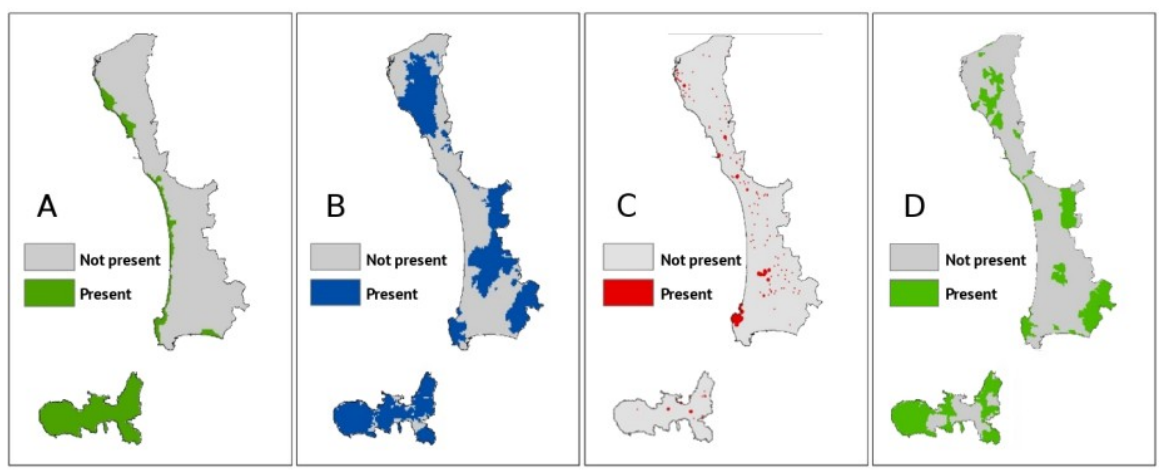

Fig. \#.4. Livorno province - maps of the distribution of the scores related to the four attributes of the Environmental Value criterion. Legend: Presence or absence of A) landscape constraints, B) hydrogeological constraints, C) archaeological constraints, D) Presence/absence of Protected areas. Source: Candura 2015.

Fig. \#.5. presents the maps of the estimated level of risk under the four Scenarios.
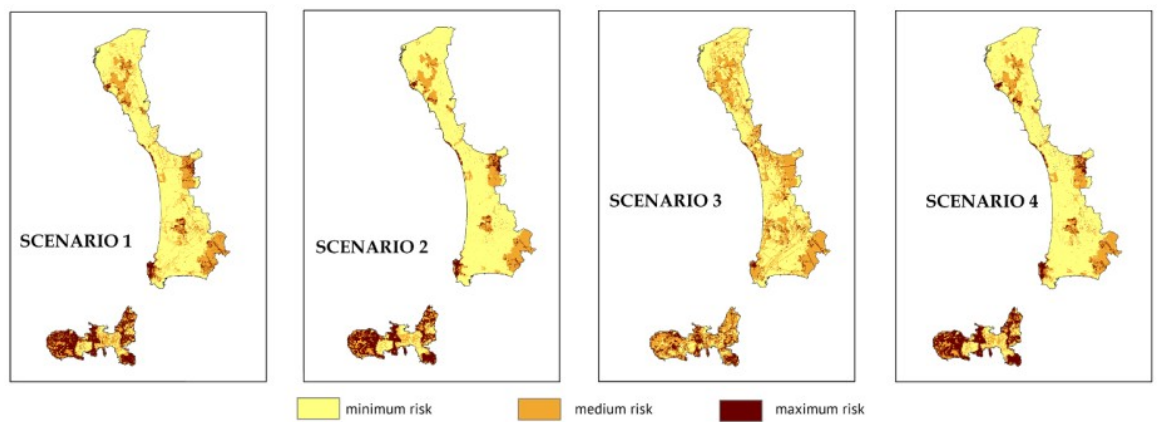

Fig. \#.5. Livorno province - maps of the level of forest fire risk, under the hypotheses of four scenarios. Source: Candura 2015, modified.

The spatial AHP model applied to GIS techniques has allowed building an integrated model of Analysis of Forest Fire Risk, as required by the current Italian legislation. The model takes into account the complexity of the relations existing among the component of the geographic, environmental, social and economic contexts and their influence on forest fires risk. While at research level there are analyses that have used more complex mathematical models to approach the problem of forest fires (Arpaci et al. 2014; You et al. 2017), in operational planning the studies on which Italian institutions in charge of territorial government have based their plans had a less transparent formalization of the concept of risk and used only a few attributes, with the consequence of a worse power of representing the risk 
situation. The map of Scenario 4 can be considered as a good compromise between model complexity and utility for planning, being a sound tool from a technical and scientific viewpoint for organizing prevention activity and structure and drawing plans for facing problems in case of fires. The model shows a high ease and flexibility of use, being implemented through the same GIS software employed by Tuscany Region for its thematic mapping and having a plug-in for MCDA analyses. Therefore, it could be improved in time by introducing new available data sources or better integrating anthropic aspects as factors determining a higher risk of forest fires. Another area of improvement could be that of the assessment of damage, where a more complex framework for estimating economic and environmental impacts might be built. Finally, it is important to highlight the role of the archive of areas where there have been forest fires that must be created and updated by law, since historical data can be very useful for testing the effectiveness of models estimating forest fire risk, as it has been done for choosing the best scenario.

\subsection{Productive and landscape restoration of a hilly rural area}

The main results of this case study are represented by the maps providing a prioritization of the areas in need of policy interventions, which have been built on the base of two different methods for summarizing the performances in terms of Cost and Benefit criteria. The spatialization of the results of the Weighted Sum and Miles' Value Index analyses are shown in Fig. \#.6 and \#.7; in both cases, according to the value of the goal, parcels have been classified as suitable for the following intervention strategies:

- Class 4 - rehabilitation to cultivation uses through extraordinary maintenance interventions;

- Class 3 - rehabilitation to cultivation uses through land improvement interventions;

- Class 2 - managed conversion into forests and woodland;

- Class 1 - natural conversion into forests and woodland (null hypothesis).

According to transacts and experts' opinion, the Weighted Sum method (Fig. \#.6) allows a better spatial distribution of classes 3 and 4 in comparison with the Value Index method (Fig. \#.7). Nevertheless, both methods allow reaching good results as regards the goal of assessing the suitability to a productive rehabilitation, which has to be interpreted in relative terms, i.e. providing a rank in terms of priority, rather than in absolute ones. 


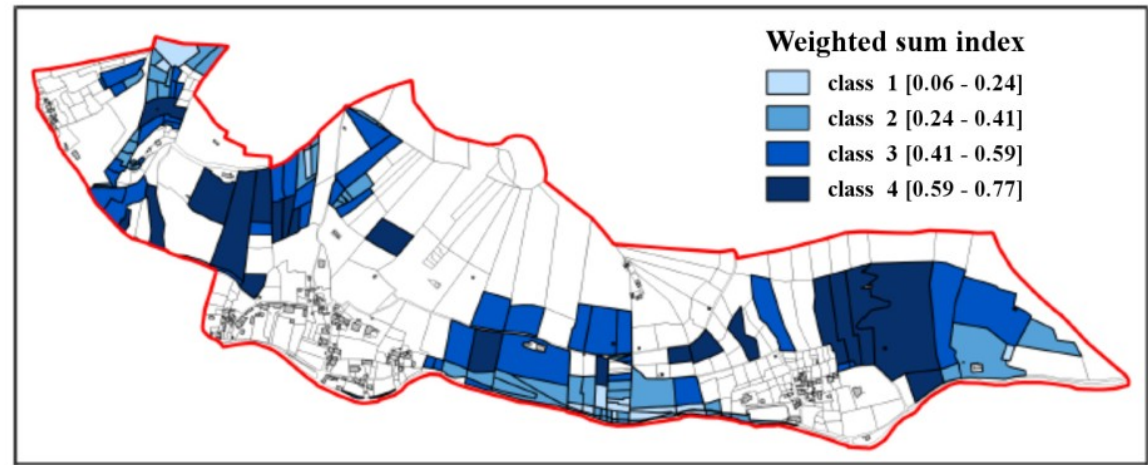

Fig. \#.6. Ranking and classification of abandoned cadastral parcels in terms of rehabilitation suitability according the Weighted Sum method. Source: Bonelli 2017.

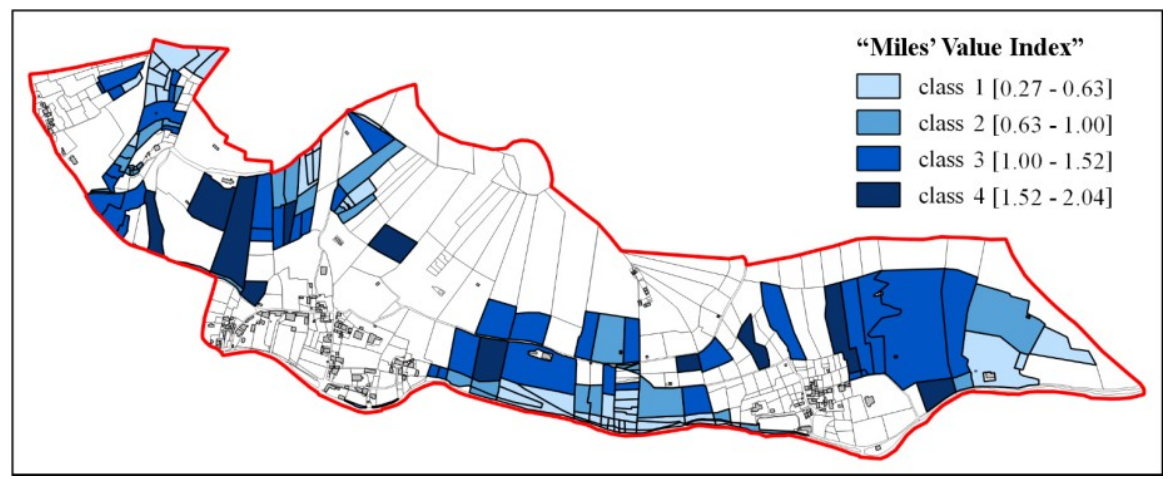

Fig. \#.7. Ranking and classification of abandoned cadastral parcels in terms of rehabilitation suitability according the Miles' Value Index method. Source: Bonelli 2017.

The main results of this case study are:

1. The identification of abandonment processes as the main driver of the transformations landscape has undergone since 1954 and a detailed territorial analysis of the areas that have been interested by these negative changes;

2. The definition of a geographic multicriteria analysis model based on the awareness that the rehabilitation to productive uses of previously cultivated areas is not always possible or cost-effective. The model, on the basis of the characteristics of abandoned land, of the cost needed for its rehabilitation and of the benefits that this latter will bring to the community well-being, especially in terms of landscape functions, identifies a set of intervention strategies ranging from the productive rehabilitation to the so called "null hypothesis", i.e. the one of "non-intervention".

These results are consistent with the two main phases in which the research has been organized, i.e. an initial phase aiming to gather knowledge, mainly through 
information taken from Tuscany Region Geo-portal, and then a phase aiming to build and run the model. Both the phases have been implemented through QGIS that has allowed to coordinate and integrate in the same database all the relevant data and to archive the indices derived from data processing. This database and the processing power of QGIS have made it easy the subsequent phase of assessment of the criteria deemed relevant for the model. Indeed, QGIS plug-in "Vector MCDA" has allowed to easily and quickly obtaining both the results of the analyses and their cartographic representation.

The strategies that have been individuated by the model should be applied to all the territory or at least to the majority of the case-study area in order to achieve a rehabilitation and promotion of its landscape, since landscape is not made of single elements or portions of a territory, but have to be considered as a whole unit. From this point of view, the results of the model could be important in setting priorities for Regional Development Programmes (RDPs) actions, e.g. in highlighting the role that could be played by Integrated Territorial Projects (ITPs), i.e. voluntary and collective private-public projects, under the Tuscany RDP 2014-2020.

Although the case-study area is quite small, the above described approach can be applied to larger rural territories having the same features, i.e. a high historic and identity value of landscape and widely spread abandonment phenomena, tailoring the criteria - when necessary - to the specific context to be analyzed. This methodology can be very useful for the public decision maker both in the phase of definition of planning rules and standards for rural territories and to channel in a more effective way the use of public resources aiming to promote and protect cultural landscapes located in hilly and mountainous areas, which are widely spread not only in Tuscany, but in the whole Italian territory.

\subsection{Planning in the rural-urban fringe taking into account the multifunctional role of agriculture}

The results of this case study mainly consist on the production of maps with specific themes (or thematisms). In particular, for each category of ESs, i.e. those concerning productive, protective, and cultural/recreational functions, a specific map was produced representing the areas providing the ESs of this category and their intensity (related to the shade intensity of the relevant color) of provision.

As regards the production of ESs on the whole, i.e. without distinguishing among categories, the problem has been faced with two different approaches. In the first case, through a new AHP, the three thematic maps have been summarized into a new map, where the intensity of color (different shades of the same color) was related to the whole production of ESs by each portion of the territory. Summarizing ESs in a composite index, by expressing them in a common monetary unit or by means of a weighted sum, would allow for compensations, meaning that a low production of ESs belonging to a category can be compensated by a high 
production of ESs belonging to another category. Although the classes with very high or very low scores have a significant role in highlighting the areas where the situation of ESs provision on the whole is highly positive or negative, the Authors deemed that this kind of information could be misleading in terms of planning actions, for the following reasons. First of all, summarizing ESs by the use of a "monetary evaluation" and additive methods might generate difficult and questionable results both from a scientific point of view, due to the complexity of the factors involved, and from an ethical point of view, due to the difficulties of interpretation of a total value obtained by the sum of values related to the provision of very different functions, affecting different groups. Then, in the case that model results are employed for spatial and urban planning, by summing up ESs and functions that are quite different, the information about the suitability of some territorial portion to produce specific ESs or ESs related to a specific function would be lost. Last, but not least, there is the risk that by summarizing ESs in a single composite index, a low score on it could be read as an index of suitability to artificialization, i.e. that the areas which have a relatively low production of ESs can be transformed in built-up or in other artificial areas without problems.

For these reasons, it was decided to avoid aggregating the values of the three categories of ESs and to produce a map with a 'three-dimensional' evaluation that keeps them separated. The map (Fig. \#.8) provides a spatial representation of the performances for the provision of ESs belonging to the three classes, which are represented by different colors. Consequently, the final shade of color depends on the mix of functions provided by each territorial ambit, so that it is possible to highlight if an area is specialized, or not, in the provision of a specific ESs category. In other words, this second map highlights the suitability of a territory to provide a specific class of ESs or a mix of them, rather than the intensity of ESs provision.

Fig. \#.8 should be interpreted more as a spatial distribution of the different categories of ESs than in terms of intensity of ESs provision, since the assessment of ESs for each category is significant in relative terms more than in absolute ones. It provides an immediate and intuitive overview of areas with greater or lower vocation to the provision of specific services or categories. This should consent to support planning by better individuating where to localize strategies aiming to promote ESs provisions, i.e. the areas with high priority in terms of protection, rehabilitation, or other interventions. In other words, Fig. \#.8 can be very useful when deciding where to concentrate aid to agricultural production, where to subsidize or promote the protection and improvement of ecological connectivity and where to promote actions related to the social and cultural role of open spaces. Last but not least, by changing the set of weights assigned to criteria, attributes and sub-attributes it is possible to build maps according to scenarios based on different sets of instances coming from stakeholders. 


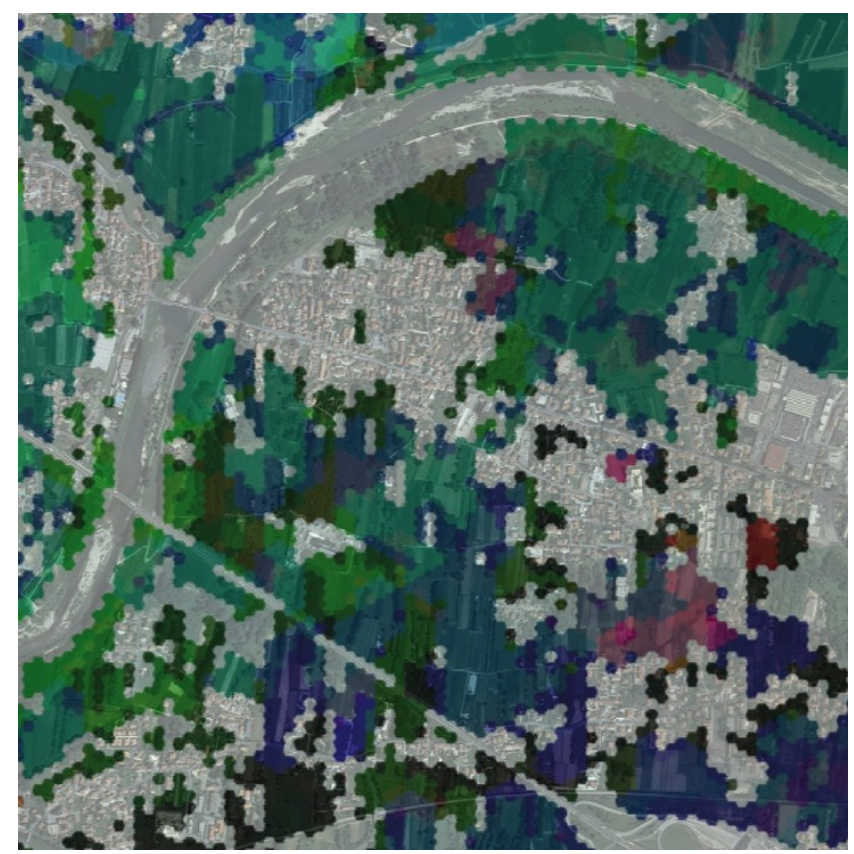

Fig. \#.8. Lucca lowland - Map of the ESs provided by agricultural land by suitability to specific category of ESs (color shadow represents the prevalence of each ESs category). Legend: green: ESs related to ecological functions; blue: ESs related to productive functions; red: ESs related to cultural/recreational functions. Source: Rovai et al. 2013.

\subsection{Sustainable governance of a cultural-historic landscape}

The governance model described in par. 2.4 has been tested on the Municipality of Castiglione d'Orcia, one of the 5 municipalities belonging to Val d'Orcia. In this paragraph, for the sake of brevity, we will focus on the farm analysis and in its utility when integrated with the results of the territorial analysis. In particular, we describe two matrices that can be very useful in designing policy tailored on the specific context of an area, the first one summarizing the results of the analyses at farm level in terms of evolutionary paths; the second one setting the more suitable policy actions according to farm evolutionary paths and territorial characteristics.

The first matrix has been built in the framework of the "farm analysis" and crosses the results in terms of Farm structural, socio-economic and management characteristics with those of Plots' suitability to cultivation. The result is the identification of seven classes of evolutionary paths of farms ranging from mainte- 
nance strategies of the current situation, to multifunctionality strategies or, in the worst cases, to the abandonment of agriculture activities (Fig. \#.9).

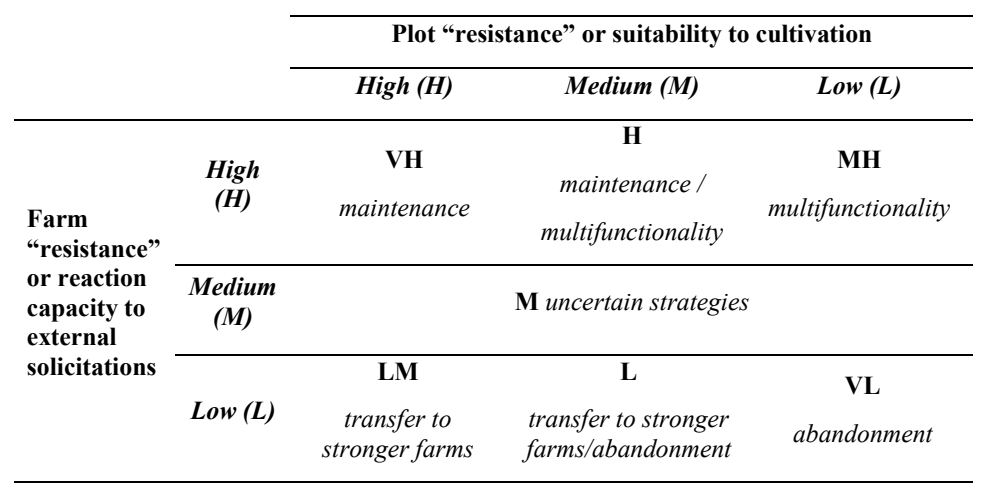

Fig. \#.9. Fuzzy classes defining farm evolutionary paths for the case study according to their adaptation capacity. Source: Rovai et al., 2016.

For example, Class VH includes farms characterized by a high adaptation capacity and by plots characterized on average by a high suitability to cultivation. These farms will very likely maintain their present cultivation systems without relevant changes in their organizational structure. Class MH represents farms with a high capability of adaptation to the external changes, but managing plots that have a low suitability to agricultural use. The evolution of these farms is almost inevitably directed to multifunctional agriculture (i.e. farm holidays, educational farms, eno-gastronomic tourism, etc.) or, alternatively, to the production of valueadded products; otherwise the low suitability to agricultural use could cause land abandonment with negative repercussions on both environmental and landscape resources. Class VL is characterized by farms with low adaptation capacity and plots with a low suitability to cultivation. These are the weakest farms, which will probably abandon all agricultural activities in the medium term, unless some supporting actions cause a rupture and a deep change of the farm development path.

By using GIS, it was possible to represent the spatial distribution of these farms in the municipality of Castiglione d'Orcia (Fig. \#.10) and to obtain important information for territorial policies: for example, farms directed to multifunctionality are mainly located on the western part of the study area, whereas the ones with a high risk of agricultural abandonment are concentrated in the central and in the eastern part of Castiglione d'Orcia municipality. Finally, those farms whose prevalent evolution will likely be the 'status quo' maintenance are mainly located in the northern part of the study area. 


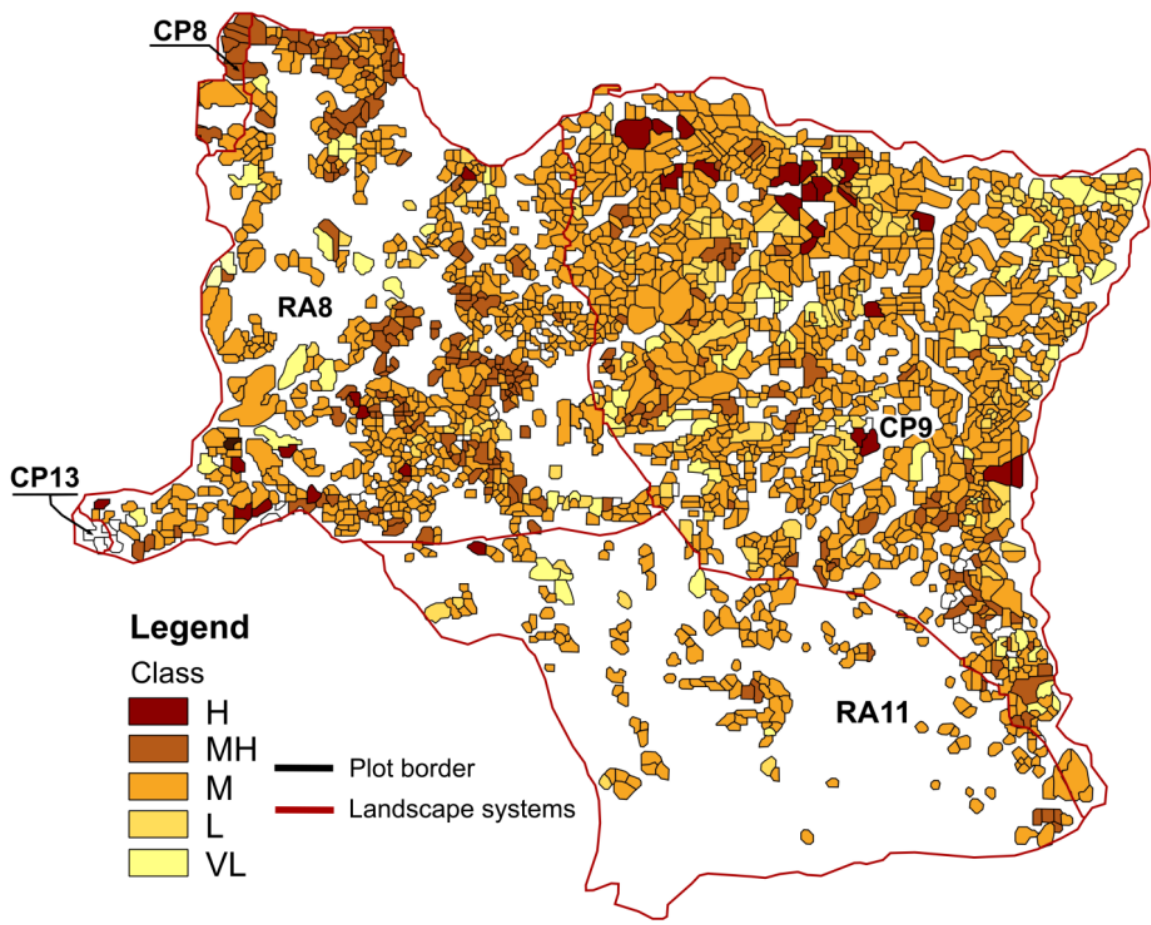

Fig. \#.10. Spatial distribution of classes related to farms evolutionary paths (H: Maintenance/Multifunctionality; MH: Multifunctionality; M: Uncertain evolution; L: Sale or renting of land to stronger farms/abandonment; VL: Abandonment). VH and LM classes have been omitted, since they are not present in the case-study area. Source: Rovai et al. 2016.

Results of the analyses, which have been validated by focus groups with local stakeholders, show that:

1. The local entrepreneurial class appears quite stable as a considerable percentage of farms presents a high adaptation capacity to the external transformations;

2. The potential impacts on environmental and landscape resources are anyway very critical as 4,356 hectares, on a total surface of 5,600, belong to farms run by farmers that may opt for agricultural abandonment if the external conditions become too adverse, i.e. due to changes on CAP, market trends and climate.

The second matrix (Fig. \#.11) combines the results of the territorial analysis, where areas were classified on the base of their level of landscape sensitivity with the ones of farms strategies. Landscape sensitivity has been obtained under the hypotheses that in the specific case-study area Intrinsic Value and Vulnerability were directly related and consequently could be summarized in a unique composite index. Priorities and actions should take into account not only the results of the analysis but also the institutional and cultural context of the area. 


\begin{tabular}{|c|c|c|c|}
\hline \multirow{2}{*}{$\begin{array}{l}\text { Farm adaptation } \\
\text { capacity (resulting } \\
\text { from farm analysis) }\end{array}$} & \multicolumn{3}{|c|}{$\begin{array}{c}\text { Landscape sensitivity } \\
\text { (resulting from territorial analysis) }\end{array}$} \\
\hline & High & Medium & Low \\
\hline$\underset{\text { Maintenance }}{\mathbf{H}}$ & $\begin{array}{l}\text { Public promotion } \\
\text { actions }\end{array}$ & $\begin{array}{c}\text { Incentives aiming } \\
\text { to improve quality } \\
\text { of landscape }\end{array}$ & $\begin{array}{c}\text { Incentives aiming } \\
\text { to improve quality } \\
\text { of landscape }\end{array}$ \\
\hline$\frac{\text { MH }}{\text { Multi-functionality }}$ & $\begin{array}{l}\text { Incentives aiming } \\
\text { to promote } \\
\text { multifunctionality }\end{array}$ & $\begin{array}{l}\text { Incentives aiming } \\
\text { to promote } \\
\text { multifunctionality } \\
\text { and to improve } \\
\text { quality of } \\
\text { landscape }\end{array}$ & $\begin{array}{c}\text { Incentives aiming } \\
\text { to improve quality } \\
\text { of landscape }\end{array}$ \\
\hline $\begin{array}{c}\mathbf{M} \\
\text { Uncertain strategies }\end{array}$ & $\begin{array}{l}\text { Incentives aiming } \\
\text { to maintain } \\
\text { agriculture } \\
\text { activities and / or } \\
\text { promote } \\
\text { multifunctionality }\end{array}$ & $\begin{array}{l}\text { Incentives aiming } \\
\text { to maintain } \\
\text { agriculture } \\
\text { activities and to } \\
\text { improve landscape } \\
\text { quality }\end{array}$ & $\begin{array}{l}\text { Incentives aiming } \\
\text { to maintain } \\
\text { agriculture } \\
\text { activities and to } \\
\text { improve landscape } \\
\text { quality }\end{array}$ \\
\hline $\begin{array}{c}\mathbf{L} \\
\text { Transfer to stronger } \\
\text { farms/abandonment }\end{array}$ & $\begin{array}{l}\text { Incentives aiming } \\
\text { to promote } \\
\text { entrepreneurial } \\
\text { "cultural change" }\end{array}$ & $\begin{array}{l}\text { Incentives aiming } \\
\text { to promote } \\
\text { entrepreneurial } \\
\text { "cultural change" } \\
\text { and to improve } \\
\text { landscape quality }\end{array}$ & $\begin{array}{l}\text { Low priority } \\
\text { interventions }\end{array}$ \\
\hline $\begin{array}{c}\mathbf{V L} \\
\text { Abandonment }\end{array}$ & $\begin{array}{l}\text { Incentives to } \\
\text { promote } \\
\text { entrepreneurial } \\
\text { "cultural change" }\end{array}$ & $\begin{array}{l}\text { Incentives aiming } \\
\text { to promote } \\
\text { entrepreneurial } \\
\text { "cultural change" } \\
\text { and to improve } \\
\text { landscape quality }\end{array}$ & $\begin{array}{l}\text { Low priority } \\
\text { interventions }\end{array}$ \\
\hline
\end{tabular}

Fig. \#.11. Response actions for the sustainable governance of the case-study rural landscape. Source: Rovai et al. 2016.

As Fig. \#.11 shows, e.g. in a subsystem with high landscape sensitivity, depending on farms probable evolution, the response actions to counteract negative effects may vary from public institution actions for the promotion of the territory, to specific regulations and incentives for the preservation of landscape's current state, up to incentives to improve farm viability in the specific territorial context. Public promotion could, e.g. include such interventions as the creation or improvement of existing countryside walking paths in order to improve territory and landscape fruition. The need of a GIS, able to collect and update all farm changes, is a consequence of the above defined response actions, since it is essential, especially for the monitoring of the most critical areas. Due to the adopted spatial scale, all those actions can be calibrated not only at farm level, but also at plot level, which makes such interventions potentially very effective.

For example, from the spatial analysis emerges that the majority of plots present high landscape sensitivity and belong to the class M (Uncertain strategies) in relation to the farm analysis. In such circumstances the definition of rules and incentives for the preservation of the current landscape configuration, together with public promotion actions for landscape valorization, becomes absolutely necessary. 
Although the definition of proper actions for promoting a sustainable rural landscape is very important, it is not possible to remain in the "scientific domain" but these actions have to be seen in the normative and administrative context where they have to be implemented. Nevertheless, in the Authors' opinion, the proposed governance model approach constitute a sound scientific tool for a sustainable governance of the rural landscape, since it is able to give suggestions about the most appropriate tools for intervention in the framework of an integrated planning approach and a prioritization of areas in need of interventions.

\section{Concluding remarks}

Planning, programming and assessing the functions of rural territories ask for the adoption of an approach to complex problems that is based on multidisciplinarity and multifunctionality of knowledge. In this framework, the integration of MCDA techniques and GIS represents a very effective and promising solution for the following reasons:

1. Multicriteria Analysis supplies many technical solutions for building a model, assessing criteria and attributes, assigning weights, testing the results; allowing a high flexibility and adaptability of the approach to a vast range of specific problems;

2. GIS software has reached a high power of processing data and information rendering, allows having a high interactivity with the user, and it can be used also with computer of normal capacity. Furthermore, due to the ability to create maps and spatial representations, it is a powerful tool for communicating with stakeholders and citizens. This characteristic is very important due to the increasing role of participative processes in the setting and implementation of territorial policies and in the assessment of their results.

In the specific case, the choice to use the same GIS software used by Tuscany Region for producing and making available geographical information, from the one hand made it easier for the Authors to access and integrate data sources, from the other hand it made the interaction with regional employees easier, since they have a good knowledge of this software.

This contribution aims to highlight these features through the analysis of the main features of four case studies characterized by an integrated approach of AHP and GIS techniques, but which are different in terms of size of the case-study area, goals, complexity of the problems, spatial elementary units considered, etc. Indeed, each approach was tailored to the specific context of application and had to be adapted to take into account data availability.

In each case of study the ability of the method to integrate information and knowledge belonging to different fields has clearly emerged as much as the capacity to represent a fundamental, scientifically robust and flexible tool providing re- 
sults able to effectively support public decision-makers for territorial planning interventions.

The use of spatial multi-criteria analysis models would make it possible to organize planning and programming as continuous and flexible processes. This is very important in all the institutional contexts, as the one of Italy, where plans and programmes have a long life time-span and for which the "ad hoc" concertation process requires too much time, so that when a plan or a program is implemented, it is already "out of date".

Finally, this tool is useful to overcome the lack of coordination among policy tools. Indeed, what is still missing in the Italian context, as in the ones of other countries, is an operative policy approach able to integrate and coordinate instances coming from stakeholders, agricultural (or other sectoral) policies and territorial and landscape governance. Consequently, efforts should be directed towards innovative policies and governance instruments, such as collective voluntary actions, integrated projects, etc., which are needed for any adequate implementation of sustainable landscape and rural development policies.

\section{References}

Arpaci, A. et al., 2014. Using multi variate data mining techniques for estimating fire susceptibility of Tyrolean forests. Applied Geography, 53, pp.258-270, https://doi.org/10.1016/j.apgeog.2014.05.015.

Barnett, J., Lambert, S. and Fry, I., 2008. The hazards of indicators: insights from the environmental vulnerability index. Annals of the Association of American Geographers, 98(1), pp.102-119, http://dx.doi.org/10.1080/00045600701734315.

Beinat, E. and Nijkamp, P. (eds.), 1998. Multicriteria analysis for land-use management, Springer Science \& Business Media.

Boroushaki, S. \& Malczewski, J., 2010. Using the fuzzy majority approach for GIS-based multicriteria group decision-making. Computers and Geosciences, 36(3), pp.302-312, https://doi.org/10.1016/j.cageo.2009.05.011.

Candura, D., 2005. Valutazione territoriale del rischio incendi nella Provincia di Livorno e piano delle infrastrutture di prevenzione e di soccorso di un'area periurbana. Università di Pisa.

Chuvieco, E. et al., 2010. Development of a framework for fire risk assessment using remote sensing and geographic information system technologies. Ecological Modelling, 221(1), pp.46-58, https://doi.org/10.1016/j.ecolmodel.2008.11.017.

Ciampi, C. et al., 2015. Tendenze recenti del cambiamento. La banca dati Uso e Copertura del Suolo di Regione Toscana. Atti Conferenza Nazionale ASITA, pp.263-270. Available at: http://atti.asita.it/ASITA2015/Pdf/081.pdf [Accessed September 14, 2017].

Conrad, E., Christie, M. and Fazey, I., 2011. Is research keeping up with changes in landscape policy? A review of the literature. Journal of Environmental Management, 92(9), pp.20972108, https://doi.org/10.1016/j.jenvman.2011.04.003.

Cooper, T., Baldock, D., Rayment, M., Kuhmonen, T., Terluin, I., Swales, V., Farmer, M., 2006. An evaluation of the less favoured area measure in the 25 member states of the European Union. Institute for European Environmental Policy, London, 249 pp, Available at: https://ieep.eu/uploads/articles/attachments/cd7c77fb-a873-4267-a6507c3bed409998/LFA_evaluation_report_full_text_en.pdf?v=63664509706, [Accessed September 14, 2017]. 
Costanza, R. et al., 1997. The value of the world's ecosystem services and natural capital. Nature, 387(6630), pp.253-260, doi:10.1038/387253a0.

Council of Europe, 2000. European Landscape Convention. Report and Convention Florence, ETS No. 17(176), p.8. Available at: http://conventions.coe.int/Treaty/en/Treaties/Html/176.htm.

Daniel T.C. and Vining J., 1983. Methodological Issues in the Assessment of Landscape Quality. In: Altman I., Wohlwill J.F. (eds) Behavior and the Natural Environment. Human Behavior and Environment (Advances in Theory and Research), vol 6. Springer, Boston, MA. https://doi.org/10.1007/978-1-4613-3539-9 3.

Eliasson, $\AA$. et al., 2010. Common criteria for the redefinition of Intermediate Less Favoured Areas in the European Union. Environmental Science and Policy, 13(8), pp.766-777. https://doi.org/10.1016/j.envsci.2010.08.003.

Farina A., 2006. Principles and Methods in Landscape Ecology - Towards a Science of the Landscape, Available from: http://www.springer.com/life+sciences/ecology/book/978-1-4020 3327-8.

Fastelli, L. et al., 2017. A spatial analysis of terrain features and farming styles in a disadvantaged area of Tuscany (Mugello): Implications for the evaluation and the design of CAP payments. Bio-based and Applied Economics, 6(1), http://dx.doi.org/10.13128/BAE-14625.

Fry, G. et al., 2009. The ecology of visual landscapes: Exploring the conceptual common ground of visual and ecological landscape indicators. Ecological Indicators, 9(5), pp.933-947, https://doi.org/10.1016/j.ecolind.2008.11.008.

Gai, C., Weng, W. and Yuan, H., 2011. GIS-based forest fire risk assessment and mapping. In Proceedings - 4th International Joint Conference on Computational Sciences and Optimization, CSO 2011. pp. 1240-1244, https://doi.org/10.1109/CSO.2011.140.

Gómez-Limón, J.A. and Sanchez-Fernandez, G., 2010. Empirical evaluation of agricultural sustainability using composite indicators. Ecological Economics, 69(5), pp.1062-1075, DOI: 10.1016/j.ecolecon.2009.11.027.

Graymore, M.L.M., Wallis, A.M. and Richards, A.J., 2009. An Index of Regional Sustainability: A GIS-based multiple criteria analysis decision support system for progressing sustainability. Ecological Complexity, 6(4), pp.453-462, https://doi.org/10.1016/j.ecocom.2009.08.006.

Greene, R. et al., 2011. GIS-Based Multiple-Criteria Decision Analysis. Geography Compass, 5(6), pp.412-432, DOI: 10.1111/j.1749-8198.2011.00431.x.

De Groot, R.S., Wilson, M.A. and Boumans, R.M.J., 2002. A typology for the classification, description and valuation of ecosystem functions, goods and services. Ecological Economics, 41(3), pp.393-408, https://doi.org/10.1016/S0921-8009(02)00089-7.

Haines-Young, R. and Potschin, M., 2013. Common International Classification of Ecosystem Services (CICES): Consultation on Version 4, August - December 2012., Available at: https://cices.eu/content/uploads/sites/8/2012/07/CICES-V43_Revised-

Final_Report_29012013.pdf [Accessed September 14, 2017]

ISPRA, 2017. Consumo di suolo, dinamiche territoriali e servizi ecosistemici - Italiano, Roma. Available at: http://www.isprambiente.gov.it/it/pubblicazioni/rapporti/consumo-di-suolodinamiche-territoriali-e-servizi-ecosistemici [Accessed September 14, 2017].

Jackson, B. et al., 2013. Polyscape: A GIS mapping framework providing efficient and spatially explicit landscape-scale valuation of multiple ecosystem services. Landscape and Urban Planning, 112(1), pp.74-88, https://doi.org/10.1016/j.landurbplan.2012.12.014.

Jaiswal, R.K. et al., 2002. Forest fire risk zone mapping from satellite imagery and GIS. International Journal of Applied Earth Observation and Geoinformation, 4(1), pp.1-10, https://doi.org/10.1016/S0303-2434(02)00006-5.

Karsak, E.E., 2004. Fuzzy multiple objective programming framework to prioritize design requirements in quality function deployment. Computers \& Industrial Engineering, 47(2-3), pp.149-163. https://doi.org/10.1016/j.cie.2004.06.001 
Labiosa, W. et al., 2010. The South Florida ecosystem portfolio model: A web-enabled multicriteria land use planning decision support system. In Proceedings of the Annual Hawaii International Conference on System Sciences, DOI: 10.1109/HICSS.2010.482.

Labiosa, W.B. et al., 2013. An integrated multi-criteria scenario evaluation web tool for participatory land-use planning in urbanized areas: The Ecosystem Portfolio Model. Environmental Modelling and Software, 41, pp.210-222, https://doi.org/10.1016/j.envsoft.2012.10.012.

Magnaghi, A., 2006. The Urban Village : A charter for democracy and local self-sustainable development, Zed Books: London, 220 pages.

Malczewski, J., 1999. GIS and multicriteria decision analysis, John Wiley \& Sons, New York, 392 pages.

Malczewski, J., 2006a. GIS-based multicriteria decision analysis: a survey of the literature. International Journal of Geographical Information Science, 20(7), pp.703-726, http://dx.doi.org/10.1080/13658810600661508.

Malczewski, J., 2006b. Ordered weighted averaging with fuzzy quantifiers: GIS-based multicriteria evaluation for land-use suitability analysis. International Journal of Applied Earth Observation and Geoinformation, 8(4), pp.270-277, https://doi.org/10.1016/j.jag.2006.01.003.

Marson, A., 2010. Land-use planning scandals in Tuscany. Mismanagement or underestimation of general public interests?, Gießen. Available at: http://www.italienforschung.de [Accessed September 14, 2017].

Mendoza, G.A. and Martins, H., 2006. Multi-criteria decision analysis in natural resource management: A critical review of methods and new modelling paradigms. Forest Ecology and Management, 230(1-3), pp.1-22, https://doi.org/10.1016/j.foreco.2006.03.023.

Miles, L.D., 1972. Techniques of value analysis and engineering, New York, NY: McGraw-Hill, 366 pages.

Millenium Ecosystem Assessment, 2005. Ecosystem and Human Well-Being: Synthesis. Island press, Washington, DC., p.1-59, Available at: https:/www.millenniumassessment.org/documents/document.356.aspx.pdf, [Accessed September 14, 2017]

OECD, 2008. Handbook on Constructing Composite Indicators METHODOLOGY AND USER GUIDE OECD publishing, ed., Available at: http://www.oecd.org/std/42495745.pdf [Accessed September 14, 2017].

Pelorosso, R. et al., 2011. Stability analysis for defining management strategies in abandoned mountain landscapes of the Mediterranean basin. Landscape and Urban Planning, 103, pp. 335-346, doi:10.1016/j.landurbplan.2011.08.007.

Primdahl, J. \& Kristensen, L.S., 2011. The farmer as a landscape manager: Management roles and change patterns in a Danish region. Geografisk Tidsskrift-Danish Journal of Geography, 111(2), pp.107-116, http://dx.doi.org/10.1080/00167223.2011.10669527.

Rovai, M. et al., 2013. Un indicatore multidimensionale per la valutazione della distribuzione spaziale dei servizi agro-ecosistemici nei territori periurbani. Atti 17ma Conferenza Nazionale ASITA - Riva del Garda, 5-7 novembre, pp.1157-1164. Available at: http://atti.asita.it/ASITA2013/Pdf/017.pdf [Accessed September 14, 2017$].$

Rovai, M. et al., 2016. A DSS model for the governance of sustainable rural landscape: A first application to the cultural landscape of Orcia Valley (Tuscany, Italy). Land Use Policy, 56, pp.217-237, https://doi.org/10.1016/j.landusepol.2016.04.038

Saaty, T.L., 1980. The Analytic Hierarchy Process. Education, McGraw Hill, New York, 287 pages, pp. 1-11

Saaty, T.L., 2004. Decision making - the Analytic Hierarchy and Network Processes (AHP/ANP). Journal of Systems Science and Systems Engineering, 13(1), pp.1-35, Available at: https://link.springer.com/content/pdf/10.1007\%2Fs11518-006-0151-5.pdf, [Accessed September 14, 2017].

Saaty, T.L., 2008. Decision making with the analytic hierarchy process. International Journal of Services Sciences, 1(1), p.83, DOI: 10.1504/IJSSCI.2008.017590 
Sands, G.R. and Podmore, T.H., 2000. A generalized environmental sustainability index for agricultural systems. Agriculture Ecosystems \& Environment, 79, pp.29-41, https://doi.org/10.1016/S0167-8809(99)00147-4.

Stoate, C. et al., 2009. Ecological impacts of early 21 st century agricultural change in Europe - A review. Journal of Environmental Management, 91(1), pp.22-46, https://doi.org/10.1016/j.jenvman.2009.07.005.

Tallis, H. and Polasky, S., 2011. Assessing multiple ecosystem services: an integrated tool for the real world. In Kareiva P., Tallis H., Ricketts T.H., Daily G.C. \& Polasky S.(eds). Natural Capital: theory and practice of mapping ecosystem services, OUP Oxford, pp.34-50.

Villa, F. and McLeod, H., 2002. Environmental vulnerability indicators for environmental planning and decision-making: Guidelines and applications. Environmental Management, 29(3), pp.335-348, https://doi.org/10.1007/s00267-001-0030-2.

Van Wagner, C., 1987. Development and Structure of the Canadian Forest Fire Weather Index System, Ottawa. Available at: http://cfs.nrcan.gc.ca/pubwarehouse/pdfs/19927.pdf [Accessed September 14, 2017].

Yang, A.L. et al., 2014. Spatial analysis of agri-environmental policy uptake and expenditure in Scotland. Journal of Environmental Management, 133, pp.104-115, https://doi.org/10.1016/j.jenvman.2013.11.038.

You, W. et al., 2017. Geographical information system-based forest fire risk assessment integrating national forest inventory data and analysis of its spatiotemporal variability. Ecological Indicators. 77, pp. 176-184, https://doi.org/10.1016/j.ecolind.2017.01.042.

van Zanten, B.T. et al., 2013. European agricultural landscapes, common agricultural policy and ecosystem services: a review. Agronomy for Sustainable Development, 34(2), pp. 309-325, https://doi.org/10.1007/s13593-013-0183-4. 